\title{
Identification of two novel amino acid polymorphisms in beta-cell liver (GLUT2) glucose transporter in Japanese subjects
}

\author{
F. Shimada ${ }^{1}$, H. Makino ${ }^{1}$, H. Iwaoka ${ }^{2}$, S. Miyamoto ${ }^{3}$, N. Hashimoto ${ }^{1}$, A. Kanatsuka ${ }^{1}$, G. I. Bell ${ }^{4}$, S. Yoshida ${ }^{1}$ \\ ${ }^{1}$ Second Department of Internal Medicine, Chiba University School of Medicine, Chiba, Japan \\ ${ }^{2}$ Narita Red Cross Hospital, Narita, Japan \\ ${ }^{3}$ Division of Endocrinology, Chiba Children's Hospital, Chiba, Japan \\ ${ }^{4}$ Howard Hughes Medical Institute and Departments of Biochemistry and Molecular Biology and Medicine, \\ University of Chicago, Chicago, Illinois, USA
}

Summary The beta-cell/liver glucose transporter (GLUT2) gene was screened for mutations using single-strand conformation polymorphism analysis (SSCP) in 30 Japanese subjects with non-insulin dependent diabetes mellitus (NIDDM). Analysis of all exons and adjacent intron regions identified six SSCP polymorphisms, three of which resulted in amino acid substitutions: V101I, T110I and G519E. The V101I and G519E substitutions represent new polymorphisms in this gene. The six polymorphisms were observed in both NIDDM and control groups and there were no significant differences in allele frequencies between groups. A portion of the insulin receptor substrate 1 gene in 30 NIDDM subjects and in normal control subjects was also screened for muta- tions. Two SSCP variants that change the sequence of the protein, $\Delta S 686 / 687$ (deletion of the codons for serine-686 and 687) and G972R, were identified in two different NIDDM subjects, both whom were also heterozygous for the V101I polymorphism in GLUT2. The GLUT2 and IRS1 amino acid polymorphisms did not show a simple pattern of co-inheritance with NIDDM in the families of these subjects suggesting that neither polymorphism is sufficient to cause NIDDM but may increase diabetes-susceptibility through their interaction with other loci and environmental factors. [Diabetologia (1995) 38: 211-215]

Key words Diabetes, glucose transporter, insulin receptor substrate-1, insulin, genetics.
Genetic factors play an important role in the development of non-insulin dependent diabetes mellitus (NIDDM), a heterogeneous disorder characterized by defects in insulin secretion as well as insulin action [1]. Mutations associated with NIDDM have been identified in the insulin [2], insulin receptor [3, 4], glucokinase [5-7] and mitochondrial genes [8,9]. This suggests that direct screening of other candidate

Received: 6 June 1994 and in revised form: 15 August 1994

Corresponding author: Dr. H. Makino, Second Department of Internal Medicine, Chiba University School of Medicine, 1-81 Inohana Chuo-ku, Chiba 260, Japan

Abbreviations: NIDDM, Non-insulin-dependent diabetes mellitus; GLUT2, glucose transporter 2; IRS1, insulin receptor substrate-1; SSCP, single-stranded conformation polymorphism; PCR, polymerase chain reaction; Thr, threonine; Phe, phenylalanine; Ala, alanine; Ser, serine; Ile, isoleucine; Val, valine; Gly, glycine. genes for mutations in a cohort of well-characterized subjects may lead to the identification of other diabetes-susceptibility loci.

GLUT2 is the glucose transporter isoform responsible for the transport of glucose across the plasma membrane of the beta cell and hepatocyte [10]. Decreased expression of this glucose transporter has been associated with defects in glucose-stimulated insulin secretion in animal models of NIDDM and IDDM $[11,12]$. The results of association studies to assess the contribution of GLUT2 to the development of NIDDM have been inconsistent [13, 14]. However, recent studies in Pima Indians have shown evidence of linkage between GLUT2 and acute insulin response. These studies also identified an amino acid polymorphism in GLUT2, T110I, although this polymorphism could not account for the linkage between GLUT2 and acute insulin response [15]. Direct screening of GLUT2 for mutations in a cohort of African-American women who had gestational 
Table 1. Clinical features of study subjects

\begin{tabular}{lll}
\hline & $\begin{array}{l}\text { NIDDM } \\
\text { patients }\end{array}$ & $\begin{array}{l}\text { Control } \\
\text { subjects }\end{array}$ \\
\hline$n$ & 30 & 48 \\
Age (years) & $47.7 \pm 2.7$ & $48.7 \pm 1.3$ \\
Body mass index $\left(\mathrm{kg} / \mathrm{m}^{2}\right)$ & $21.7 \pm 0.4$ & $22.9 \pm 0.4$ \\
Age at diagnosis (years) & $37.5 \pm 3.3$ & - \\
Family history of diabetes & $56.7 \%$ & $0 \%$ \\
Treatment & & \\
Diet & $23.3 \%$ & \\
Oral agent & $36.7 \%$ & \\
Insulin & $40.0 \%$ & \\
\hline
\end{tabular}

diabetes and developed NIDDM after delivery identified 12 nucleotide substitutions, two of which gave rise to amino acid substitutions, T110I and V197I, the former being also present in Pima Indians [16]. In vitro expression studies showed that the Ile-110 variant was able to efficiently transport 2-deoxyglucose whereas the Ile-197 variant was functionally inactive, suggesting that GLUT2 mutations may cause NIDDM [17].

We have screened GLUT2 for mutations using single stranded conformation polymorphism (SSCP) in a cohort of 30 unrelated Japanese subjects with NIDDM. Six nucleotide substitutions were identified, three of which resulted in amino acid substitutions including V101I and G519E as well as the previously identified T110I.

\section{Materials and methods}

Subjects. Thirty subjects with NIDDM and 48 normal control subjects were studied (Table 1). The control subjects had no family history of diabetes and normal glucose tolerance on administration of a 75-g oral glucose tolerance test. The diagnosis of NIDDM was based on World Health Organisation criteria [18]. All patients were informed of the purpose of study and gave their informed consent. These studies were approved by the ethics committee of Chiba University Hospital.
Screening for nucleotide substitutions in GLUT2 and insulin receptor substrate-1. DNA was isolated from human lymphocytes. The 11 exons and adjacent introns of GLUT2 [19] were amplified using polymerase chains reaction ( $P C R$ ) and primers specific for each exon. A region of IRS1 [20] representing amino acids 445 to 1028 [21] was also screened for mutations by SSCP. (The sequences of the primers used to amplify GLUT2 and IRS1 are available from the authors on request). Standard PCR conditions were used with ${ }^{32} \mathrm{P}$-labelled primers. The PCR products were diluted 15 -fold with formamide buffer $(95 \%$ formamide, $0.05 \%$ bromphenol blue and $0.05 \% \mathrm{xy}$ lene cyanol), heated at $95^{\circ} \mathrm{C}$ for $3 \mathrm{~min}$ and $1.5 \mu \mathrm{l}$ of each sample was loaded onto a $5 \%$ non-denaturing polyacrylamide gel $\left(30 \times 40 \times 0.03\right.$; acrylamide: $N, N^{\prime}$-methylene-bis-acrylamide $=$ 49:1). Each sample was run on four gels containing 0 or $10 \%$ glycerol at room temperature or $4{ }^{\circ} \mathrm{C}$. The gels were then transferred to paper, dried and exposed to film (XAR-5; Kodak, Rochester, N.Y., USA) with an intensifying screen for $12 \mathrm{~h}$ at $-70^{\circ} \mathrm{C}$. The sequences of novel bands observed by SSCP were determined directly and also after subcloning the amplified DNA into M13.

\section{Statistical analysis}

Data are given as mean \pm SEM. The association of polymorphisms with NIDDM was analysed by $2 \times 2$ contingency tables and the significance of difference was tested by a Fisher's exact test.

\section{Results}

Polymorphisms in GLUT2. Six SSCP variants were identified on screening the entire protein coding region of GLUT2 together with adjacent intron segments in 30 Japanese subjects with NIDDM (Table 2). The T110I polymorphism, the silent substitutions in the codons for Thr-198 and Phe-479, and the $\mathrm{C} / \mathrm{T}$ polymorphism $15 \mathrm{bp}$ before the splice-acceptor site of exon 5 have been described previously. The substitutions V101I and G519E represent new polymorphisms/variants [16]. The V101I was most easily identified by SSCP in a $5 \%$ polyacrylamide gel with

Table 2. Polymorphisms in GLUT2 and IRS-1 in Japanese subjects

\begin{tabular}{|c|c|c|c|c|c|c|}
\hline & \multirow[t]{2}{*}{ Location } & & \multirow[t]{2}{*}{ Nucleotide change } & \multirow[t]{2}{*}{ Amino acid } & \multicolumn{2}{|c|}{ Allele frequency (\%) } \\
\hline & & & & & NIDDM $^{\mathrm{a}}$ & Control $^{b}$ \\
\hline \multirow[t]{6}{*}{$\overline{\text { GLUT2 }}$} & Exon3 & Codon 101 & GTA $\rightarrow$ ATA & $\mathrm{Val} \rightarrow \mathrm{Ile}$ & 7.3 & 4.2 \\
\hline & Exon $3^{c}$ & Codon 110 & $\mathrm{ACT} \rightarrow \mathrm{ATT}$ & $\mathrm{Thr} \rightarrow \mathrm{Ile}$ & 4.2 & 3.1 \\
\hline & Exon10 & Codon 519 & $\mathrm{GGA} \rightarrow \mathrm{GAA}$ & Gly $\rightarrow$ Glu & 1.0 & 1.0 \\
\hline & Exon $4 B^{c}$ & Codon 198 & $\mathrm{ACG} \rightarrow \mathrm{ACA}$ & Thr $\rightarrow$ Thr & 4.2 & 3.1 \\
\hline & Intron $5^{\mathrm{C}}$ & & $\mathrm{C} \rightarrow \mathrm{T}$ & & 4.2 & 3.1 \\
\hline & Exon10 & Codon 479 & TTC $\rightarrow$ TTT & Phe $\rightarrow$ Phe & 22.9 & 27.0 \\
\hline \multirow[t]{3}{*}{ IRS-1 } & Codon $686 / 687$ & & $\triangle \mathrm{AGC} / \mathrm{AGC}$ & $\Delta$ Ser/Ser & 1.0 & 0 \\
\hline & Codon 972 & & $\mathrm{GGG} \rightarrow \mathrm{AGG}$ & Gly $\rightarrow$ Arg & $1.0^{\mathrm{d}}$ & 0 \\
\hline & Codon 805 & & $\mathrm{GCA} \rightarrow \mathrm{GCG}$ & Ala $\rightarrow$ Ala & 39.6 & 37.5 \\
\hline
\end{tabular}

${ }^{a} n=96$ (48 individuals, including 30 subjects screened by SSCP and 18 others); ${ }^{b} n=96$ (48 individuals); " These polymorphisms were found in the same subjects and thus may be in linkage disequilibrium; ${ }^{d}$ this substitution was found only in members of the FA family 
FA

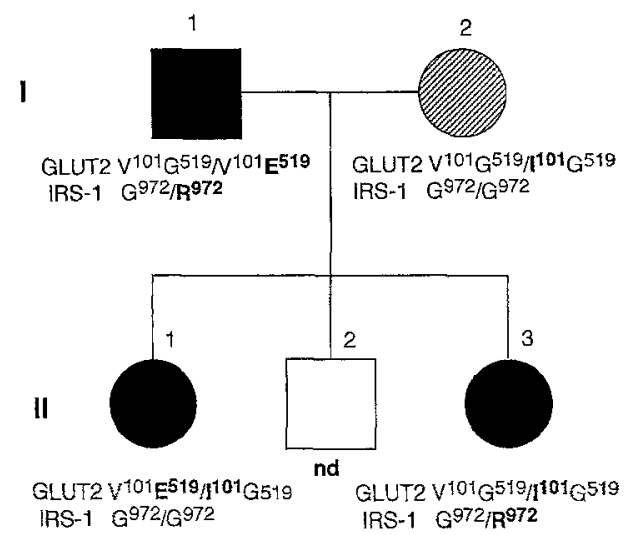

FB

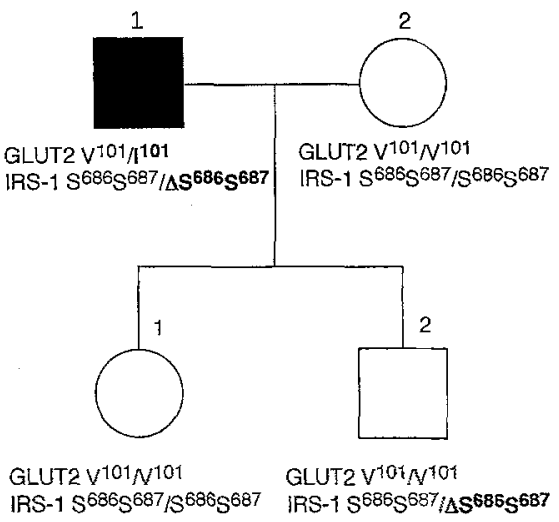

Fig. 1. Pedigree of NIDDM subjects with both GLUT2 and IRS1 polymorphisms. Male $\square$; female $\bigcirc$; closed symbols, individuals with NIDDM; diagonal shading, individuals with impaired glucose tolerance; open symbols, individuals with normoglycaemia; nd, individual who was not available for testing. Genotypes are noted under each symbol. Bold type indicates variant amino acids
$10 \%$ glycerol at room temperature and G519E with a $5 \%$ polyacrylamide gel without glycerol at $4{ }^{\circ} \mathrm{C}$. We also tested 18 additional subjects with NIDDM and 48 non-diabetic subjects for these polymorphisms. There was no difference in frequency of any of these polymorphisms between NIDDM and non-diabetic groups (Table 2).

The G519E variant was identified in an NIDDM subject who was also heterozygous for the V101I polymorphism (Fig.1). Thus, this subject (FA II-1) was a compound heterozygote. Characterization of the pattern of segregation of these two polymorphisms in the subject's family indicated that the allele haplotypes are $\mathrm{I}^{101} \mathrm{G}^{519}$ and $\mathrm{V}^{101} \mathrm{E}^{519}$; the native haplotype is $\mathrm{V}^{101} \mathrm{G}^{519}$.

Polymorphisms in IRS1. Almid et al. [22] have reported two amino acid variants/polymorphisms in IRS1, A513P and G972R, and suggested that amino acid polymorphisms in IRS1 may be involved in the development of NIDDM. We screened the region of amino acids 445 to 1028 of IRS1 for mutations in 30 Japanese subjects with NIDDM. Three SSCP variants were noted (Table 2): a silent substitution in the codon for Ala-805 (GCA/GCG), the G972R polymorphism, and a six nucleotide deletion resulting in the deletion of the codons for Ser-686 and Ser 687 $(\Delta \mathrm{S} 686 / 687)$. We also tested 18 additional subjects with NIDDM and 48 non-diabetic subjects for G972R and $\Delta S 686 / 687$. These variants were found in one NIDDM subject each and in none of the non-diabetic subjects (Table 2 ).

Presence of GLUT2 and IRS1 amino acid polymorphisms in the same subject. The two IRS1 amino acid polymorphisms were present in subjects with the V101I polymorphism in GLUT2, one of whom was also a compound heterozygote of GLUT2 (Fig.1). Analysis of the co-segregation of the GLUT2 and IRS1 variants with NIDDM in these families did not show a simple pattern of inheritance.

\section{Discussion}

GLUT2 is the major glucose transporter expressed in beta cells and hepatocytes and plays a central role in the regulation of glucose metabolism in these cells. Diabetes is characterized in part by the inability of the beta cell to secrete insulin in response to glucose whereas the response to non-glucose secretagogues is retained, and it has been proposed that decreased expression of beta-cell GLUT2 is responsible for the loss of the glucose-stimulated insulin secretory response [23]. The decreased levels of GLUT2 may impair the glucose-stimulated insulin secretory response by reducing high $\mathrm{K}_{\mathrm{m}}$ glucose transport. They may also affect glucose responsiveness directly by uncoupling GLUT2 and cellular proteins and/or structures involved in glucose signalling such as glucokinase. In this regard Hughes et al., [24] have shown that the heterologous expression of GLUT2 confers glucose responsiveness to non-beta cells.

If decreased GLUT2 expression impairs glucose sensing, mutations in GLUT2 may have a similar effect. Four amino acid polymorphisms V10I, T110I, V197I and G519E have now been described in GLUT2 (Fig. 2). They are located in transmembrane segments 2 (V101 and T110) and 5 (V197), and the intracellular COOH-terminal domain (G519). The T110I and V197I mutations have been expressed in vitro. The Ile-110 change had no effect on 2-deoxyglucose uptake whereas the Ile-197 change abolished transport activity [17]. The effect of substitutions at Val-101 and Gly-519 on GLUT2 transport activity have not been determined. The residue Val-101 is invariant in sequences of the mammalian facilitative glucose/fructose transporter family [25, 26], and thus its mutation may affect transporter activity or function. However, the V101I substitution was present in both NIDDM and non-diabetic subjects suggesting that its presence per se is not sufficient to cause NIDDM although it may contribute to the development of NIDDM in the presence of other genetic or acquired 


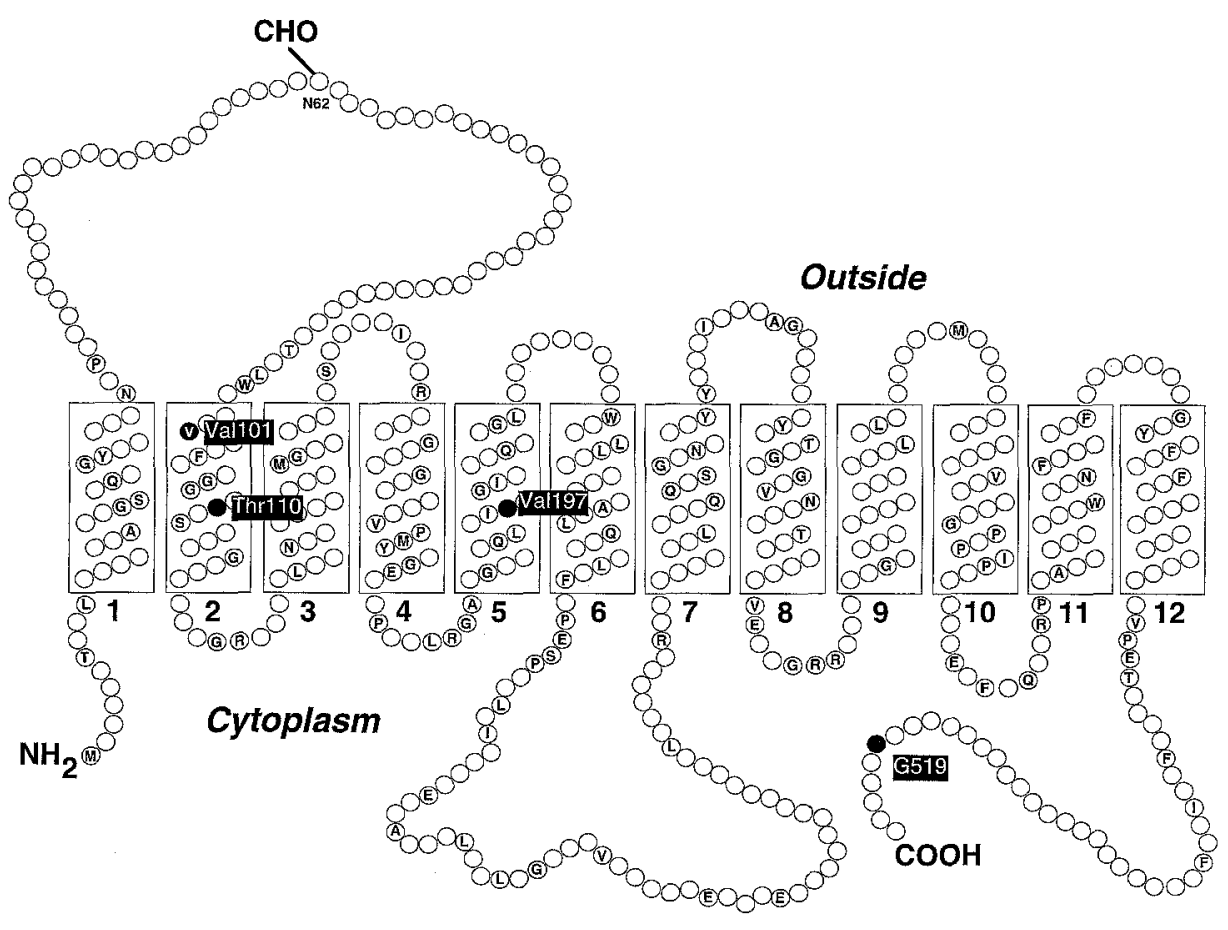

Fig. 2. Model for the orientation of GLUT2 in the plasma membrane. The 12 transmembrane-spanning $\alpha$ helical segments are shown as boxes and are numbered $1-12$. The potential site for $\mathrm{N}$-glycation in the extracellular loop connecting transmembrane segments 1 and 2 is noted by "CHO". Invariant residues in the facilitative glucose/fructose transporter family are shown using the single-letter abbreviations for the amino acids. The four residues in which amino acid polymorphisms/ mutations have been identified are shown as filled circles and labelled defects in beta-cell function and insulin action or both. The residue Gly-519 in GLUT2 is not conserved and is Gly in the human and rat and Ala in mouse [26], and its effect on beta-cell function is unknown.

During the course of this study, two families were identified that were segregating amino acid polymorphisms in both GLUT2 and IRS1 together with NIDDM. This may be coincidental or may suggest that both loci contribute to the development of NIDDM. However, the pattern of inheritance of the GLUT2 and IRS1 polymorphisms with NIDDM was not consistent with a simple model for genetic liability. The identification of additional families in which these polymorphisms are segregating may resolve their relative contribution to the development of glucose intolerance and diabetes.

Acknowledgements. We thank Drs. S. Seino (Chiba University) and Y. Tokuyama (University of Chicago) for their helpful advice. This research was supported by grants from the Ministry of Education, Science and Culture, Japan (No. 05670840), Otsuka Pharmaceutial Co. Ltd., Ishii Clinic, Howard Hughes Medical Institute, NIH (DK-20595), and Bristol-MyersSquibb.

\section{References}

1. DeFronzo RA, Bonadonna RC, Ferrannini E (1992) Pathogenesis of NIDDM: a balanced overview. Diabetes Care $15: 318-368$

2. Steiner DF, Tager HS, Chan SJ, Nanjo K, Sanke T, Rubenstein AH (1990) Lessons learned from molecular biology of insulin gene mutations. Diabetes Care 13:600-609

3. Taylor SI, Cama A, Accili D et al. (1992) Mutations in the insulin receptor gene. Endocrine Rev 13:566-595
4. Makino H, Taira M, Shimada F et al. (1992) Insulin receptor gene mutation: a molecular genetical and functional analysis. Cell Signal 4:351-363

5. Froguel Ph, Zouali H, Vionnet $\mathrm{N}$ et al. (1993) Familial hyperglycemia due to mutation in glucokinase. $\mathrm{N}$ Engl $\mathrm{J}$ Med 328:697-702

6. Hattersley AT, Turner RC, Permutt MA et al. (1992) Linkage of type 2 diabetes to the glucokinase gene. Lancet 339:1307-1310

7. Shimada F, Makino H, Hashimoto N et al. (1993) Type 2 (non-insulin-dependent) diabetes mellitus associated with a mutation of the glucokinase gene in a Japanese family. Diabetologia 36:433-437

8. Ballinger SW, Shoffner JM, Hedaya EV et al. (1992) Maternally transmitted diabetes and deafness associated with a $10.4 \mathrm{~kb}$ mitochondrial DNA deletion. Nature Genetics $1: 11-15$

9. van der Ouweland JMV, Lemkes HHPJ, Ruitenbeek W et al. (1992) Mutation in mitochondrial tRNA ${ }^{\text {Leu(UUR) }}$ gene in a large pedigree with maternally transmitted type II diabetes mellitus and deafness. Nature Genetics 1:368371

10. Fukumoto H, Seino S, Imura $H$ et al. (1988) Sequence, tissue distribution and chromosomal localization of mRNA encoding a human glucose transporter-like protein. Proc Natl Acad Sci USA 85:5434-5438

11. Johnson JH, Ogawa A, Chen L et al. (1990) Under expression of $\beta$ cell high $\mathrm{K}_{\mathrm{m}}$ glucose transporters in non insulindependent diabetes. Nature 250:546-549

12. Thorens B, Wu YJ, Leahy JL, Weir GC (1992) The loss of GLUT2 expression by glucose-unresponsive $\beta$ cells of ob/ $\mathrm{ob}$ mice is reversible and is induced by the diabetic environment. J Clin Invest 90:77-85

13. Matsutani A, Koranyi L, Cox N, Permutt MA (1990) Polymorphisms of GLUT2 and GLUT4 genes. Use in evaluation of genetic susceptibility to NIDDM in blacks. Diabetes 39:1534-1542

14. Alcolado JC, Baroni MG, Li SR (1991) Association between a restriction fragment length polymorphism at the li- 
ver/islet cell (GLUT2) glucose transporter and familial type 2 (non-insulin-dependent) diabetes mellitus. Diabetologia 34:734-736

15. Janssen R, Bogardus C, Takeda J et al. (1994) Linkage analysis of acute insulin secretion with GLUT2 and glucokinase in Pima indians and the identification of a missense mutation in GLUT2. Diabetes 43:558-563

16. Tanizawa Y, Riggs AC, Chiu KC et al. (1994) Variability of the pancreatic islet beta cell/liver (GLUT2) glucose transporter gene in NIDDM patients. Diabetologia 37:420-427

17. Mueckler M, Kruse M, Strubs M, Riggs AC, Chiu KC Permutt MA (1994) A mutation in the GLUT2 glucose transporter gene of a diabetic patient abolishes transport activity. J Biol Chem 269:17765-17767

18. Diabetes mellitus: report of a WHO Study Group (1985) WHO Tech Rep Ser 727; Geneva pp 1-113

19. Takeda J, Kayano T, Fukumoto H, Bell GI (1993) Organization of the human GLUT2 (pancreatic $\beta$-cell and hepatocyte) glucose transporter gene. Diabetes 42:773-777

20. Araki E, Sun XJ, Haag BL et al. (1993) Human skeletal muscle insulin receptor substrate-1: characterization of the cDNA, gene, and chromosomal localization. Diabetes 42:1041-1054
21. Nishiyama M, Wands JR (1992) Cloning and increased expression of an insulin receptor substrate-1-like gene in human hepatocellular carcinoma. Biochem Biophys Res Commun 183:280-285

22. Almind K, Bjorbaek C, Vestergaard H, Hansen T, Echwald S, Pedersen O (1993) Aminoacid polymorphisms of insulin receptor substrate- 1 in non-insulin-dependent diabetes mellitus. Lancet 342:828-832

23. Milburn JL, Ohneda M, Johnson JH, Unger RH (1993) $\beta$ cell GLUT2 loss and non-insulin-dependent diabetes mellitus: current status of the hypothesis. Diabetes Metab Rev 9:231-236

24. Hughes SD, Quaade C, Johnson JH, Ferber S, Newgard CB (1993) Transfection of AtT-20ins cells with GLUT-2 but not GLUT-1 confers glucose-stimulated insulin secretion: relationship to glucose metabolism. J Biol Chem 268:1520515212

25. Bell GI, Burant CF, Takeda J, Gould GW (1993) Structure and function of mammalian facilitative sugar transporters. J Biol Chem 268:19161-19164

26. Burant CF, Sivitz WI, Fukumoto H et al. (1991) Mammalian glucose transporters: structure and molecular regulation. Recent Prog Horm Res 47:349-388 